\section{"A NOTE ON CYCLING."}

To the Elditor's of THE LANOET.

SIRS,-As a cyclist of over a quarter of a century (I first rode in 1872) I feel I must challenge Dr. Campbell's statements regarding posture and reasons given for less fatigue in cycling compared to walking.

First, regarding posture, it stands to reason that if the dorsal curve of the spine is exaggerated the ribs must necessarily come closer together and so impede thoracic movements. Diaphragmatic respiration is encouraged therefore. The intervertebral discs are pressed upon and, in proportion to the length of time the position is assumed, they are made wedge-shaped, the spinal ligaments are modified by vibration to this position, and the"result is kyphosis bicyclistarum in those cases where Dr. Campbell's graceful curve of back is made to harmonise with the wheel rims for hours and oays together. I have ridden all sorts of "safeties," various makes of "ordinary" (varying from a 56 in. to a 62 in.), the old Ariel, and the iron-rimmed " bone-shaker," and my experience is that the intervertebral discs, though capable of much recuperation after malposition in riding, are very sensitive to jarring and vibration. To ride an iron-rimmed bone-shaker with a curved back would be fraught with dire discomfort subsequently. My theory is this-that so long as the lumbar curve of the spine is a forward one-i.e., so long as its convexity is anterior-it is quite allowable to bend the spine forward as a whole, so that the resistance to the atmosphere is diminished; but if the lumbar curve is obliterated and made continuous with the dorsal one the position is faulty. I speak with more authority than most cyclists for I have made many trials and being $6 \mathrm{ft} .6 \frac{1}{2}$ in. in height a faulty position of the spine in my case soon "tells."

Regarding the second point, as to increased endurance, the whole hinges upon carrying versus rolling a weight. In cycling we roll our own weight; gearing gives leverage (third order) and diminishes muscular movements; ballbearings diminish friction, and pneumatic tyres are to the cycle what steel rails are to the train and locomotive. I am willing to admit Dr. Campbell's comparative anatomy, but if the erect position were such an effort to maintain as be suggests, then I for one ought to find walking a most arduous exercise. In practice I do not; I can walk all day and do a mile in eleven minutes, therefore although Dr. Campbell's suggestions regarding diminished distance from head to feet may apply in some cases he cannot lay it down as a universal fact.

I am, Sirs, yours faithfully,

G. G. GIDLEY, M.R.C.S. Eng, L.P.C.P. Lond.

Cullompton, Devon.

\section{A QUESTION OF TITLE.}

\section{To the Editors of THE LANCET.}

SIRS,-The modern development of professional ethics has quite determined that a practitioner shall not advertise him self as a Doctor of Medicine when he is a Licentiate of the College of Physicians only and so on. Is it not quite a parallel indiscretion for a hospital to advertise itself as the "Cancer Hospital" when members of its staff admit cases of uterine myoma and perform "panbysterectomy" without making ic clear that they at least tad the excuse of a mistake in diagnosis?

I am, Sirs, yours faithfully, LAWSON TAIT.

Newhall-street, Birmingham, Nov, 26th, 1897.

\section{"SURGICAL SYMPTOMS IN CONNEXION WITH FILARIA SANGUINIS." \\ To the Editors of THE LANOET.}

Sins, - In ThE LANCET of Oct. 9th last is an annotation on an interesting paper on Filarial Diseases of the Lymphatics, read by Surgeon-Lieutenant-Colonel W. K. Hatch before the Bombay Medical and Physical Society. Everyone must sympathise with Surgeon-Lieutenant-Colonel Hatch in the unfortunate issue of the case upon which he reluctantly operated, but at the same time the evidence afforded by the symptoms point to death having been due to some cause unconnected with the disease of the lymphatics. In any case I submit that it is hardly rational to condemn this operation on the results of an isolated case.
In an article on this subject ${ }^{1} I$ drew attention to the fact that twenty-four operations of this nature had been performed during the last seven years in the Madras General Hospital and in none of these cases did any serious symptoms arise. In carrying out the operation care should be taken as far as possible to secure all the lymphatic vessels before they are divided. If, in spite of this procaution, leakage should occur, firm pressure should be applied by means of a sponge which is included within the dressings. If these precautions be adopted the wound will generally heal by first intention. Cases of filarial lymphangiectasis of the spermatic cord are treated in the same manner and with the same precautions. Experience has confirmed me in the opinion that operative measures are called for in many cases of lymphangiectasis of filarial origin. Not only is there a prospect of securing some of the parental worms, a result which I have in several instances achieved, but there is also the prospect of relieving the patient from the serious annoyance caused by recurring attacks of inflammation. There are no doubt certain cases in which there have been attacks of chyluria or in which there are other evidences to show that the seat of obstruction is at some point high up in the lymphatic system that is not suitable for operation. Putting such cases aside the operation is one which, in my opinion, may be confidently recommended as ho!ding out a prospect of relief to the patient and one which involves but little risk.

I am, Sirs, yours faithfully,

J. Maitland, M.D. Edin., Surgeon-Lieutenant-Colonel.

General Hospital, Madras, Nov. 11th, 1897.

\section{ON A SOPHISTICATED SYRUP OF FERROUS} IODIDE.

To the Editors of THE LANOET.

SIRS,-May I be allowed to call attention to the fact that much of the syrup of ferrous iodide now found in the pharmacies contains hypophosphorous acid in appreciable quantities. The responsibility for this seems to rest on certain London firms who prepare syrupoids or solutions for the preparation of these syrups alleging them to produce more elegant syrups than the methods of the Pharmacopceia. The presence of the hypophosphorous acid being quite unlooked for may explain how it is that syrupus ferri iodidi so often produces gastric troubles in young chiidren. I am, Sirs, your obedient servant,

Dublin, Nov. 29th, 1897. J. C. McWALTER, L.R.C.S. Irel.

\section{“THE IMMEDIATE TREATMENT OF THE DEFORMITY OF SPINAL CARIES."}

\section{To the Rditors of THE LANOET.}

SIRs,- The paper which we read on this subject before the Clinical Society of London on Nor. 12th was brought forward by us for certain specific purposes which were therein detailed-viz, to demonstrate the feasibility and safety of this method in suitable cases. The question of ultimate results was one with which a paper founded upon cases of four months' duration could not pretend to deal nor did it attempt to do so. As such it was accepted for reading. It is a matter of great satisfaction to us that you in your editorial article of Nov. 20 th and in common with other medical periodicals have granted our theses and in the following words: "(1) That angular curves of the spine can very generally be straightened by the exhibition of an amount of force wéll within the limits of safety; (2) that this treatment is not attended with grave immediate danger if carried out with due care; and (3) that curves of long duration and great extent may yield to this treatment."

There appear, however, to be two discrepancies in your editorial article to which we wish to allude. In the first place we fail to understand how, in view of the three conclusions to which you had already come, the next statement can be substantiated-vjz, "the demonstration was of value and interest solely as indicating the method adopted and the extent to which curves of the spine will yield to force." And in the second place in an early part of your remarks you speak of the method as "an altered form of an old and discarded treatment of Pott's disease of the spine," and later 